\title{
The Use of Reading Strategies Amongst Saudi University EFL Students
}

\author{
Sultan Altalhab ${ }^{1}$ \\ ${ }^{1}$ Curriculum and Instruction Department, College of Education, King Saud University, Riyadh, Saudi Arabia \\ Correspondence: Sultan Altalhab, Curriculum and Instruction Department, College of Education, King Saud \\ University, Riyadh, Saudi Arabia. E-mail: saltalhab@ksu.edu.sa
}

Received: March 1, 2019

Accepted: March 20, 2019 Online Published: May 27, 2019

doi:10.5539/jel.v8n3p234

URL: https://doi.org/10.5539/jel.v8n3p234

\begin{abstract}
This study examined the use of reading strategies amongst Saudi EFL university students, exploring which strategies are perceived to be the most frequently used. Additionally, this study also aimed to explore gender differences in Saudi EFL university students' adoption of reading strategies. The total number of the participants in this study was 148 students ( 75 male, 73 female) and they completed a questionnaire on the use of reading strategies. The results revealed that Saudi EFL university students were aware of most types of reading strategies. No significant differences were found between male and female students in the use of reading strategies. A noteworthy finding was that most of the students were likely to spend limited time, only 15 minutes or less a day reading English texts.
\end{abstract}

Keywords: reading, strategies, gender

\section{Introduction}

Reading English texts is considered one of the ways to develop language-learning, mainly vocabulary, as several studies have shown. It also plays a role in improving other aspects, such as writing. 'After all, reading is the basis of instruction in all aspects of language learning: using textbooks for language courses, writing, revising, developing vocabulary, acquiring grammar, editing, and using computer assisted language learning programmes' (Mikulecky, 2008, p. 12). One of the most important types of reading is critical reading, which is described by Alderson (2000, p. 8) as reading 'beyond the lines'. Therefore, learners should be able to read what a text implies. Hedge (2003) refers to the purposes of reading in language courses, including the ability to read a wide range of texts in English, building a knowledge of language which will facilitate reading ability, building schematic knowledge, the ability to adapt to the reading style according to reading purpose (e.g., skimming, scanning), developing an awareness of the structure of written texts in English, and taking a critical stance to the contents of the texts.

Reading has been defined as 'the ability to draw meaning from the printed page and interpret this information appropriately' (Grabe \& Stoller, 2002). 'Reading is a psycholinguistic process. It requires partial use of available minimal language cues selected from perceptual input on the basis of the reader's expectation' (Yukselir, 2014, p. 66). The ultimate goal of reading is then achieving comprehension. Reading comprehension is a very complex process that involves interactions between the reader, text, purpose and context (Snow, 2002). Yukselir (2014) shares the same view on reading comprehension as a result of a complicated process between a number of elements such as, text, setting, reader background, reading strategies, and the role of L1. This suggests reading is influenced by a number of factors that play a role in reading comprehension.

\section{Literature Review}

\subsection{Types of Reading}

The EFL research divides EFL reading into two types: 'intensive reading', wherein the student reads short texts; and 'extensive reading', wherein the student reads long texts. It has been explained that extensive reading 'entails learners reading as much as possible, for the purpose of pleasure or information rather than learning particular language features', with extensive reading typically being 'self-selected' (Al-Homoud \& Schmitt, 2009, p. 383). The primary difference between the intensive and extensive types of reading therefore lies in the length of the text being read by the student. Whilst short texts are read in the case of intensive reading, extensive 
reading is characterised by a large amount of L2 input combined with the absence, or minimal requirement, of specific tasks related to the reading material (Hafiz \& Tudor, 1989).

Based on the above definitions from the existing research, intensive reading can therefore be seen in activities, such as reading course books. Here, the learner will typically be required to read a short text whilst performing a number of exercises, tasks or tests that focus on reading comprehension, vocabulary, grammar, and discourse (Nation, 2001). Conversely, extensive reading can be seen in the case of graded readers, which are books written in the target language that have been edited to 'stay within a strictly limited vocabulary ... typically divided into several levels' (Nation, 2001, p. 162). Thus, whilst intensive reading is typically associated with short task-based exercises, extensive reading is typically associated with the consumption of reading material based on the learner's overall language proficiency.

According to Nation (2001), EFL learners in particular may have little opportunity to interact with the English language other than reading English texts and books. This argument highlights the importance of books and reading in language learning. Furthermore, this also suggests that ESL learners may have an advantage over EFL learners in that the latter students may not have had the same level of exposure to the English language as their ESL counterparts. In relation to this point, Nation and Gu (2007) suggest that teachers could help students to learn new words encountered through intensive reading by providing students with the meanings of the words and potentially also teaching students how these words should be pronounced. The meanings of new words can be introduced quickly using various techniques, including translating the words through the student's native language, using drawing to express meaning, providing synonyms for the word, explaining the meaning using the second language, or through the use of real-world objects.

In other work, Al-Homoud and Schmitt (2009) compared data from an extensive reading class with a more traditional class that entailed intensive reading tasks. The primary focus of the comparison was to measure the impact of reading type on students' reading comprehension, reading speed and vocabulary gains, as well as to determine the attitudes of students towards each type of reading. The reading classes were part of a 10 -week pre-sessional course at a Saudi university, with four 50-minute classes held per week. Numerous problems were encountered in the extensive reading class, including attendance by students with relatively low proficiency, a predominant lack of interest in reading for pleasure amongst the students, and the course being too short in duration. The study involved 70 participants, who were divided into two groups. The first group engaged in intensive reading, whilst the second group engaged in extensive reading. The results of the study indicated that the extensive reading participants reported much more positive attitudes towards reading, their class and their own learning compared to the participants in the intensive reading group. Based on the findings, the researchers concluded that extensive reading was as good as, or better than, intensive reading.

This study is one of the few studies that have focused on extensive reading in a classroom environment over a longer period of time. Additionally, it should also be noted that various materials and tests were used in the reading classes, with readers of different grading levels being given to the students in the extensive reading group. This enabled testers to measure any improvements in students' reading ability level. However, the number of words that were taught to students in the intensive reading group was large, at 20-30 words per reading class. This may have made it difficult for the teacher to fully explain the meaning of these words within each 50-minute session, which could have impacted students' learning. The findings of the study were in alignment with the results of Al-Nafisah's (2015) study, which explored the effectiveness of extensive reading on reading comprehension amongst 54 Saudi EFL university students. Al-Nafisah found that extensive reading had a positive impact on students' reading comprehension.

A recent study conducted by Endris (2018) examined the effect of extensive reading on EFL learners' attitudes and reading ability levels. An analysis of data gathered from $92 \mathrm{EFL}$ learners indicated that extensive reading has a positive impact on both students' attitudes towards extensive reading and their reading comprehension. Nevertheless, Endris asserted that extensive reading should be carried out over an extended time period and in conjunction with motivating activities for optimum impact.

A large-scale study involving 460 Saudi EFL university students was also conducted by Al-Nafisah and Al-Shorman (2011) to determine the level of interest in different types of reading amongst Saudi EFL students. The students' greatest reading interests were found to be stories, adventure books, and books about religion; magazines about the internet, computers, and technological advancements; and newspaper articles on world events. Interestingly, the results of the study also highlighted the main challenges that students associated with reading, allowing for insight into the barriers to reading for EFL students. These challenges included rarely being able to visit the library, the difficulty involved in being able to obtain books quickly, the lack of availability of 
reading materials, time constraints, a lack of local libraries, and the belief that there were better things to do than to read.

Whether intensive or extensive, reading can be practised when learners read the text aloud. Gibson (2008) outlined the advantages and disadvantages of reading aloud, also highlighting how the disadvantages could be minimised. She recognised that reading can be perceived as a tedious activity, particularly amongst students and also recognised that reading does not necessarily improve pronunciation, since the texts used are often unnatural and, as a result, do not typically develop pronunciation in spontaneous speech. Given that reading is usually considered a silent activity, reading aloud is not often promoted as an essential skill for students to develop. One of the main issues associated with reading is that even native speakers can find reading aloud difficult. Consequently, reading aloud can have a negative impact on students' overall motivation to read. However, since students may rely on their native language when silently reading English language texts, reading aloud may help learners to develop their L2 pronunciation to a greater degree. Additionally, this might be the only occasion when shy learners are able to practise in class. Gibson (2008) asserts that the disadvantages of reading aloud may be minimised through the use of certain teaching strategies, such as asking students to listen for specific information within the content that is being read aloud. Another strategy is to help reduce the reader's anxiety by asking students to read aloud for a shorter period of time or read only to small groups instead of the whole class. Using these strategies, students may be less likely to develop an aversion to reading and may therefore be better able to benefit from the advantages of reading materials written in the target language. Gibson's (2008) study sought to understand the aims of using reading-aloud tasks in English language learning by interviewing 12 native-speaking English teachers, 15 non-native English-speaking teachers, and 7 ESL learners. Here, the non-native English-speaking teachers and ESL learners were considered autonomous learners. The participants reported that they engaged in reading-aloud exercises for several reasons, such as to improve their pronunciation and fluency, as well as to gain speaking practice. The majority ( $82 \%$ ) of autonomous learners reported that they practised reading aloud by themselves. Interestingly, all of the students stated that they enjoyed reading aloud during lessons and found it to be a useful activity. Based on the findings, the researcher concluded that the benefits of reading aloud could outweigh the disadvantages or challenges associated with reading aloud if the activity is employed properly. However, in order to determine whether reading-aloud activities impact L2 vocabulary learning, it is necessary to conduct further empirical research on this topic.

Alshumaimeri (2011) examined the effectiveness of reading aloud on the reading comprehension of 145 Saudi secondary school students by comparing it with silent reading and subvocalisation. The students were asked to read three different passages, with each passage being read either silently, aloud, or through subvocalisation. The findings indicated that compared to the other two types of reading activity, reading aloud had the greatest positive impact on students' reading comprehension. Additionally, the majority of students reported that they preferred reading aloud to silent or subvocalised reading. It is well recognised that reading comprehension is one of the most important aspects of reading skill. However, it could be said that one of the limitations of Alshumaimeri's study is that it measured reading comprehension using a single type of test (multiple choice). It is possible that the findings may have varied if other measures or question types were included in the research.

Both Gibson (2008) and Alshumaimeri (2011) focused on reading aloud as an activity that can be practised autonomously by learners, whether in or out of the classroom. However, neither researcher explored the value of this activity in the classroom setting. It is possible that different results may have been presented if reading aloud had been investigated within a reading class, particularly given that teachers' feedback may play a crucial role in shaping learners' perspectives and behaviours. For instance, some students may not like to be interrupted while reading and may find this off-putting. Furthermore, one study indicates that students can become demotivated when receiving direct corrections from teachers, with students also becoming distracted from the meaning of the texts in this scenario (Moghaddam, Nasiri, Zarea, \& Sepehrinia, 2012, p. 217). With this being said, teachers' feedback appears to be helpful in improving students' pronunciation, whether the student reads the text or listens to a classmate reading it. When giving feedback on engagement in reading-aloud exercises, teachers often focus on the students' accuracy rather than fluency. Therefore, it may be beneficial for teachers to balance the type of feedback given in order to help improve both fluency and accuracy.

In summary, although most of the studies reviewed in this section focused on the use and impact of extensive reading rather than intensive reading, both types of reading have been found to be useful in language learning. Given that intensive reading is most commonly associated with the materials included in textbooks, it appears that further research is required to establish the effectiveness of intensive reading with regards to teaching L2 vocabulary. Knowing the learner's level of competence is also important in order to determine which texts are the most appropriate for teaching. 


\subsection{Reading Strategies}

Abbott (2006, p. 637) defines reading strategies as 'the mental operations or comprehension processes that readers select and apply in order to make sense of what they read'. Research on reading has shown that whilst reading comprehension is not an automatic process, it is influenced by the adoption of a certain reading strategy (Yukselir, 2014). It is suggested in the research that there are three types of reading strategies: 'pre-reading strategies, during-reading strategies and post-reading strategies' (Cekiso \& Madikiza, 2014, p. 2). Pre-reading strategies provide learners with a general idea about the topic and enable them to develop an expectation of what will be read (Al-Issa, 2006). These strategies are adopted during the initial stage before learners begin reading the text, and they appear to be helpful in gaining an overview of the text. During-reading strategies allow learners to manage problems, and they include strategies such as guessing the meaning from context (AD-Heisat, 2009). Post-reading strategies, as the final type of strategy, refer to strategies that enable learners to make conclusions and generalisations after reading the text (Cekiso, 2007).

Mokhtari and Reichard (2002) provided three classifications for reading strategies: Global Reading Strategies, Problem-Solving Strategies, and Support Reading Strategies. Global Reading Strategies (GLOB) are defined as reading strategies that 'set the stage for the reading act'; Problem-Solving Strategies (PROB) are defined as 'focused problem solving or repair strategies' that are primarily used 'with the inception of different problems in understanding textual information'; and Support Reading Strategies (SUP) are defined as 'support mechanisms' that 'function as sustaining responsiveness to reading' (Hatami \& Asl, 2017, p. 1225).

In the Saudi context, Al-Nujaidi (2003) explored the reading strategies used by Saudi EFL students using a questionnaire survey. The findings suggested that the students employed most of the reading strategies included in the instrument with either moderate or high frequency. The results also suggested that the participants were aware of most types of reading strategy. Problem-solving strategies were the mostly highly recognised strategies according to the students' responses, with the least recognised strategies being critical reading techniques such as evaluating information in the text, summarising the text to improve comprehension, using typographical aids in the text, and checking the characteristics of the text. The study also explored the role of gender in the adoption of reading strategies, with the findings indicating that female students are significantly more likely to adopt reading strategies compared to male students. This finding is supported by Alsamadani (2009), who examined the relationship between Saudi EFL students' reading comprehension and adoption of reading strategies, finding female students to demonstrate significantly higher use of reading strategies along with higher reading comprehension compared to males. The research findings also suggested that reading comprehension is significantly impacted by the reading environment, with the participants also reporting that they used planning strategies more frequently than attending or evaluating strategies. However, the use of reading strategies was not found to be significantly related to reading comprehension level in this study.

The association between reading comprehension and the teaching of reading strategies has also been explored in other studies. For instance, Kei (2011) examined the effect of teaching two reading strategies (teaching vocabulary in advance and pre-questioning) on the reading comprehension of Japanese EFL university students. The findings indicated that teaching vocabulary in advance was less effective than pre-questioning in improving students' reading comprehension. These findings contradict the results of Hayashi's (1999) study, in which it was suggested that reading widely in L1 or L2 played a greater role in developing reading strategies than teaching reading strategies, with the findings highlighting the importance of extensive reading in improving learners' vocabulary and reading.

\subsection{Research Aims and Questions}

Several researchers (e.g., Al-Homoud \& Schmitt, 2009; Al-Nafisah, 2015) have referred to the challenges that Saudi EFL learners encounter when practising reading. Al-Homoud and Schmitt (2009, p. 383) also have described the Saudi context as a 'challenging environment' with regards to students' ability to practise reading.

Given the above point, this study aims to provide insight into the types of reading strategies employed by Saudi EFL university students, the amount of time that Saudi EFL university students spend reading English texts, and the gender differences that may exist in the adoption of reading strategies. In light of the studies reviewed in the previous section, along with the need for further and more recent research in this area, the present study aims to answer the following research questions:

1) What are the most frequently used reading strategies as perceived by Saudi EFL university students?

2) Are there any significant differences in the use of reading strategies between male and female Saudi EFL university students? 


\section{Methodology}

\subsection{Participants}

A total of 148 participants were involved in this study, with an approximately equal number of males $(\mathrm{n}=75)$ to females $(n=73)$. All of the participants were EFL learners majoring in English at King Saud University, with all of the participants having started learning English at primary school at the age of 10 years old.

\subsection{Research Instrument}

Data on reading strategies were gathered from participants using a structured questionnaire. The questionnaire employed in this research was adapted from the questionnaire used in Al-Nujaidi's (2003) study, which was originally based on Mokhtari and Sheorey's (2002) Survey of Reading Strategies (SORS). The first item in the questionnaire asked participants to state how much time they typically spend reading English texts, with a total of 36 reading strategies then outlined. Participants were asked to state the frequency of use for each reading strategy.

\subsection{Data Analysis}

The collected data were analysed using independent and paired sample t-tests in order to compare inter- and intra-group differences using the Statistical Package for Social Sciences (SPSS). Descriptive statistics were also used to analyse the data. Inter-group differences were analysed using the independent sample t-test, whilst intra-group differences were analysed using the paired sample t-test.

\section{Results and Discussion}

In order to address the first research question ('What are the most frequently used reading strategies as perceived by Saudi EFL university students?'), the mean values for the frequency of adoption for each of the reading strategies were calculated using descriptive statistics. The mean scores were then categorised based on the frequency of use, with scores of 4.31 and above considered to be high, scores of 3.51-4.30 considered to be moderate, and scores of 3.50 and below considered to be low. Table 1, below, illustrates the results of the questionnaire data analysis, highlighting the strategies most frequently used by participants.

Table 1. The reading strategies that the participants thought that they used the most

\begin{tabular}{lllll}
\hline Item no. & Statement & Category & Mean & Std. Deviation \\
\hline 1 & Translating. & SUP & 4.93 & 1.33 \\
2 & Re-reading. & PROB & 4.74 & 1.23 \\
3 & Paying closer attention to reading. & PROB & 4.55 & 1.28 \\
4 & Getting back on track upon losing concentration. & PROB & 4.51 & 1.35 \\
5 & Guessing meaning of unknown words. & PROB & 4.49 & 1.27 \\
6 & Using dictionary. & SUP & 4.39 & 1.53 \\
7 & Using context clues. & GLOB & 4.38 & 1.38 \\
8 & Underlining and highlighting. & SUP & 4.24 & 1.49 \\
9 & Using prior knowledge. & GLOB & 4.23 & 1.44 \\
10 & Checking understanding upon reaching new information. & GLOB & 4.18 & 1.24 \\
\hline
\end{tabular}

The highest overall mean score was 4.93 , with the lowest being 2.83 . The results indicated that the participants were aware of most of the reading strategies outlined in the questionnaire, with the strategies perceived to be the most frequently-used being 'translating', 're-reading', and 'paying closer attention to reading'. Most of the strategies were problem-solving strategies. Additionally, the questionnaire data showed that the participants adopt the majority of strategies at a moderate rate. The reading strategies that were perceived to be the least frequently used included 'reading aloud when text becomes difficult' (SUP), 'evaluating what is read' (GLOB) and 'using typological aids' (GLOB). The results suggest that the participants involved in this study tend to employ problem-solving reading strategies rather than global reading strategies or support strategies.

Similarities were found when comparing the results of the current study to that of other studies conducted in a similar context. The reading strategies thought to be the most frequently used in the current study were similar to those found in Al-Nujaidi's (2003) research, although different samples were recruited. However, the results do contradict the findings of Hatami and Asl (2017), who found support strategies to be the most frequently-adopted reading strategies based on the perceptions of participants. It is possible that the variation in findings may be due to the different contexts in which the studies have been conducted. 
The second research question ("Are there any significant differences in the use of reading strategies between male and female Saudi EFL university students?') was addressed through the conduction of the t-test. The findings indicate that there were no significant differences between male and female students with regards to the use of reading strategies $(t=1.465, \mathrm{df}=140.30, \mathrm{p}=.145)$. The results are illustrated in Table 2, below.

Table 2. Differences between male and female students in relation to the use of reading strategies

\begin{tabular}{llllllll}
\hline Gender & $\mathrm{N}$ & Mean & Std. Deviation & Std. Error Mean & T-test & df & Sig. \\
\hline Male & 75 & 144.04 & 22.09 & 2.55 & 1.465 & 140.30 & .145 \\
Female & 73 & 138.18 & 26.35 & 3.08 & & & \\
\hline
\end{tabular}

These findings contradict the results of Al-Nujaidi's (2003) and Alsamadani's (2009) research, where it was found that female students were significantly more likely to adopt reading strategies than male students. It should be noted, however, that the questionnaire utilised in Alsamadani's (2009) research was quite different from the questionnaire used in the current study, which may account for the difference in findings.

Table 3. The amount of time the participants spend reading English texts

\begin{tabular}{llll}
\hline Factor & & Number & Percent \\
\hline Time & Nothing & 20 & 13.5 \\
& 15 minutes or less & 61 & 41.2 \\
& Half an hour & 33 & 22.3 \\
& One hour & 15 & 10.1 \\
& $1-2$ hours & 14 & 9.5 \\
& 2 hours or more & 5 & 3.4 \\
Total & & 148 & 100 \\
\hline
\end{tabular}

The results indicate that the majority of students are likely to spend just 15 minutes or less reading English texts per day. This finding is in accordance with the findings of other researchers (e.g., Al-Homoud \& Schmitt, 2009; Al-Nafisah, 2015; Al-Nafisah \& Al-Shorman, 2011) and suggests that the lack of time spent reading may be one of the challenges that Saudi EFL learners encounter when practising reading. Since reading is considered one of the most important inputs in the development of language, as various robust research studies have shown, this finding may go some way to explain the low level of proficiency amongst Saudi EFL learners suggested by a number of researchers (e.g., Al-Seghayer, 2011).

\section{Conclusion}

This study has examined the reading strategies perceived to be most frequently employed by Saudi EFL university students. The findings indicated that students were aware of most reading strategies, with global reading strategies being the main area of focus. The results also suggested that there was no significant difference between male and female students with regards to the adoption of reading strategies, which was in contradiction with other studies. Additionally, it was shown that Saudi EFL learners spend only a very limited amount of time reading English texts on a daily basis, which may hinder their language development. Based on the results of the study, it is recommended that EFL teachers encourage students to engage in reading practise more frequently. Additionally, it is also recommended that teachers directly teach students a range of reading strategies to support them in reading English texts and improving their language ability.

Inevitably, there are a number of limitations in this study. It should be noted that the use of a single research instrument can be considered a limitation. Therefore, it is suggested that further research may be conducted on this topic using a number of other data collection instruments, such as interviews and diaries. It is unknown to what extent the students are competent in using these strategies; therefore, further research in this area would be helpful. Further research is also needed to explore the challenges that learners face when practising reading. This may provide additional insights that could not be captured in the present study.

\section{References}

Abbott, M. L. (2006). ESL reading strategies: Differences in Arabic and Mandarin speaker test performance. Language Learning, 56(4), 633-670. https://doi.org/10.1111/j.1467-9922.2006.00391.x
Alderson,
J. C. (2000).
Assessing reading.
Cambridge:
Cambridge University
Press. 
https://doi.org/10.1017/CBO9780511732935

Al-Homoud, F., \& Schmitt, N. (2009). Extensive reading in a challenging environment: A comparison of extensive and intensive reading approaches in Saudi Arabia. Language Teaching Research, 13(4), 383-401. https://doi.org/10.1177/1362168809341508

Al-Issa, A. (2006). Schema theory and L2 reading comprehension: Implications for teaching. Journal of College Teaching \& Learning, 3(7), 41-48. https://doi.org/10.19030/tlc.v3i7.1700

Al-Nafisah, K. I. (2015). The effectiveness of an extensive reading programme in developing Saudi EFL university students' reading comprehension. Arab World English Journal, 6(2), 98-109. https://doi.org/10.24093/awej/vol6no2.8

Al-Nafisah, K., \& Al-Shorman, R (2011). Saudi EFL students' reading interests. Journal of King Saud University-Languages and Translation, 23(1), 1-9. https://doi.org/10.1016/j.jksult.2009.07.001

Al-Nujaidi, A. (2003). Relationship between vocabulary size, reading strategies, and reading comprehension of EFL learners in Saudi Arabia. Unpublished Doctoral Thesis, Oklahoma State University, Stillwater.

Alsamadani, H. (2009). The relationship between Saudi EFL college-level students' use of reading strategies and their EFL reading comprehension. Unpublished Doctoral Thesis, Ohio University, Athens.

Al-Seghayer, K. (2011). English teaching in Saudi Arabia: Status, issues, and challenges. Riyadh: Hala Print CO. https://doi.org/10.7575/ijalel.v.2n.1p.221

Alshumaimeri, Y. (2011). The effects of reading method on the comprehension performance of Saudi EFL students. International Electronic Journal of Elementary Education, 4(1), 185-195.

Cekiso, M. P. (2007). Evaluating reading strategies instruction. Unpublished Doctoral Thesis, North-West University, Potchefstroom.

Cekiso, M., \& Madikiza, N (2014). Reading strategies used by Grade 9 English Second Language learners in a selected school. Reading \& Writing-Journal of the Reading Association of South Africa, 5(1), 1-7. https://doi.org/10.4102/rw.v5i1.42

Endris, A. A. (2018). Effects of extensive reading on EFL learners' reading comprehension and attitudes. International Journal of Research in English Education, 3(4), 1-11. https://doi.org/10.29252/ijree.3.4.1

Gibson, S. (2008). Reading aloud: A useful learning tool? ELT Journal, 62(1), 29-36. https://doi.org/10.1093/elt/ccm075

Grabe, W., \& Stoller, F. L. (2002). Teaching and researching: Reading. Harlow, UK: Longman

Hafiz, F. M., \& Tudor, I. (1989). Extensive reading and the development of language skills. ELT Journal, 43(4), 413. https://doi.org/10.1093/elt/43.1.4

Hatami, M., \& Asl, H. D. (2017). The Reading Strategies Used by EFL Students: A Case of Iranian Advanced English Language Learners. Journal of Language Teaching and Research, 8(6), 1223-1228. https://doi.org/10.17507/jltr.0806.26

Hayashi, K. (1999). Reading strategies and extensive reading in EFL classes. RELC Journal, 30(2), 114-132. https://doi.org/10.1177/003368829903000207

Hedge, T. (2003). The Practice of English Language Teaching. ELT Journal, 57(4), 401-405. http://doi.org/10.1093/elt/57.4.401

Kei, M. (2011). Effects of Pre-Reading Strategies on EFL/ESL Reading Comprehension. TESL Canada Journal, 28(2), 51-73. https://doi.org/10.18806/tesl.v28i2.1072

Mikulecky, B. S. (2008). Teaching reading in a second language. London: Pearson.

Moghaddam, M. S., Nasiri, M., Zarea, A., \& Sepehrinia, S. (2012). Teaching pronunciation: The lost ring of the chain. Journal of Language Teaching \& Research, 3(1). https://doi.org/10.4304/jltr.3.1.215-219

Mokhtari, K., \& Reichard, C. A. (2002). Assessing students' metacognitive awareness of reading strategies. Journal of Educational Psychology, 94(2), 249-259. https://doi.org/10.1037//0022-0663.94.2.249

Mokhtari, K., \& Sheorey, R. (2002). Measuring ESL students' awareness of reading strategies. Journal of Developmental Education, 25(3), 2-11.

Nation, I. S. P. (2001). Learning vocabulary in another language. Cambridge: Cambridge University Press. https://doi.org/10.1017/CBO9781139524759. 
Nation, I. S. P., \& Gu, P. Y. (2007). Focus on Vocabulary. Sydney: Macquarie University.

Snow, C. E. (2002). Reading for understanding: Toward a research and development programme in reading comprehension. Pittsburgh, PA: RAND.

Yukselir, C. (2014). An investigation into the reading strategy use of EFL prep-class students. Procedia-Social and Behavioral Sciences, 158, 65-72. https://doi.org/10.1016/j.sbspro.2014.12.034

\section{Copyrights}

Copyright for this article is retained by the author, with first publication rights granted to the journal.

This is an open-access article distributed under the terms and conditions of the Creative Commons Attribution license (http://creativecommons.org/licenses/by/4.0/). 